\title{
THE EFFECTS OF NATURAL ZEOLITE AND SILANE COUPLING AGENTS ON MELTING AND CRYSTALLIZATION BEHAVIOUR OF POLYPROPYLENE
}

\author{
D. Basalp and F. Tihminlioğg ${ }^{*}$ \\ Department of Chemical Engineering, Faculty of Engineering, İzmir Institute of Technology, Gülbahçe, 35430, Urla/İzmir, Turkey
}

\begin{abstract}
The thermal characterization of polypropylene (PP) composites containing untreated and treated zeolite with different silane coupling agents was carried out using thermogravimetric analysis (TG) and differential scanning calorimetry (DSC) to investigate the effects of natural zeolite and surface modifiers on melting, crystallization and degradation behaviour of PP. 3-aminopropyltriethoxysilane (AMPTES), methyltriethoxysilane (MTES) and 3-mercaptopropyltrimethoxysilane (MPTMS) were used as surface modifiers at four different concentrations ( $0.5-2.0$ mass $\%$ ). Thermal analyses indicated that silane treatment and $2-6$ mass $\%$ zeolite addition have no significant effect on the melting and degradation temperatures of the composites. The crystallization temperatures of the composites were increased due to the nucleating effect of the zeolite. The influence of the modifiers on the interactions between PP and zeolite was determined by the activities of untreated and treated zeolite. The maximum interactions leading to good adhesion were observed in the AMPTES treated composites. Also, non-isothermal crystallization kinetics of the composites was analyzed using Avrami and Kissinger models.
\end{abstract}

Keywords: crystallization, degradation, natural zeolite, non-isothermal crystallization kinetics, polypropylene, silane coupling agents

\section{Introduction}

Polypropylene (PP) is one of the most important commercial polymers due to its superior properties such as high chemical resistance and low density. Fillers $\left(\mathrm{CaCO}_{3}, \mathrm{Mg}(\mathrm{OH})_{2}\right.$, talc, mica, etc.) or reinforcing agents (glass fibre) are used in many applications of PP such as in household, automotive and packaging industry to enhance the properties of PP (stiffness, gas permeability, heat resistance, flame retardance, etc.), and to reduce the cost. In spite of the advantages of the fillers, the incorporation of the hydrophilic fillers into PP leads to the loss in the mechanical properties and also the changes in the thermal properties of PP. However, the mechanical properties of polymer composites can be improved by using silane coupling agents as those reported in the literature [1-7].

Also, the previous study done by our group on the effects of interfacial interactions on the mechanical properties of PP-natural zeolite composites has indicated that silane coupling agents provide significant improvement in the mechanical properties of the composites [8]. Furthermore, although there are many studies related to the effects of silane coupling agents on the mechanical properties of polymer composites [1-8], the number of studies related to the effects of filler modification on the thermal properties of the composites is limited [9-11].
Thermal behaviour of polymer composites is important in the determination of end use applications and processing methods of polymer articles. Generally, thermal degradation and crystalline properties of polymer composites can be analyzed by thermogravimetric analysis (TG) and differential scanning calorimetry (DSC) [12-14]. In this study, it was aimed to investigate the effect of silane coupling agents and natural zeolite on the thermal properties of PP using DSC and TG. Particularly, non-isothermal crystallization kinetics of the natural zeolite filled PP composites was investigated to determine the effect of cooling conditions on crystallization properties. The crystallization properties affect mechanical and transport properties of polymer composites [15-17]. Because of the importance of crystallization process, non-isothermal crystallization kinetics also was investigated using Avrami and Kissinger models for the determination of spherulite growth rate and crystallization activation energy, respectively.

\section{Theory}

Characterization of polymer composites by $T G$

TG is based on the mass loss of a sample due to the formation of volatile products as a function of temperature. TG is used to characterize the decomposi- 
tion and thermal stability of polymer composites. However, TG can be used also in the determination of additives such as plasticizer or filler and evaluation of moisture, volatiles and residues in a material $[13,18]$.

\section{Characterization of polymer composites by DSC}

Differential scanning calorimetry (DSC) is used to determine the thermal transition of a polymer such as melting, degradation, crystallization and glass transition temperatures. DSC takes place in a variety of applications such as determination of the heat of fusion, the specific heat as a function of temperature, the degree of crystallinity, kinetic parameters and the oxidative stability of a polymer [19].

The addition of various types of fillers such as $\mathrm{CaCO}_{3}$, talc or zeolite to the polymer influences the crystallinity and also the mechanical properties of polymers. The crystallinity of the composites can be calculated from DSC measurements. The crystallinity index $(\chi)$ is the ratio of the measured melting enthalpy $\left(\Delta H_{\mathrm{m}}, \mathrm{J} \mathrm{g}^{-1}\right)$ of the polypropylene composite to the value of enthalpy of $100 \%$ crystalline polypropylene $\left(\Delta H_{0}=209 \mathrm{~J} \mathrm{~g}^{-1}\right)[19,20]$.

$$
\chi=\frac{\Delta H_{\mathrm{m}}}{\Delta H_{0}}
$$

The crystallization kinetics of polymers can be described by Avrami equation given in Eq. (2).

$$
\alpha=1-\exp \left(-k t^{\mathrm{n}}\right)
$$

where $\alpha$ and $n$ denote the fraction of the transformed material in the time $t$ and a constant characteristic of the process, respectively. The value of $n$ is a function of the crystal growth and nucleation mechanism, $k$ describes the rate of crystallization. Although the Avrami model has been widely used to describe the isothermal crystallization process and also used for non-isothermal processes [21, 22], the Kissinger method can be also used for the determination of the crystallization kinetics parameters given in Eq. (3).

$$
\frac{\mathrm{d} \alpha}{\mathrm{d} t}=A \exp \left(-\frac{E}{R T}\right)(1-\alpha)^{\mathrm{n}}
$$

where $\alpha, A, E, T$ and $n$ are fraction reacted, frequency factor, activation energy, temperature and reaction order, respectively.

The Kissinger equation is used to obtain the activation energy of crystallization from the variation in the peak temperature with heating rate. Kissinger's method assumes that the maximum in the DSC curve occurs at the same temperature as the maximum reaction rate. Equation (3) can be written in the form of Eq. (4) when the maximum reaction rate occurs at $\mathrm{d} / \mathrm{d} t(\mathrm{~d} \alpha / \mathrm{d} t)=0$.

$$
\frac{E \phi}{R T_{\mathrm{p}}^{2}}=A n(1-\alpha)^{\mathrm{n}-1} \exp \left(-\frac{E}{R T_{\mathrm{p}}}\right)
$$

where $\phi$ is the cooling rate and $T_{\mathrm{p}}$ is the temperature at which the maximum conversion rate occurs in the DSC curve. Equation (4) can be rearranged to obtain activation energy from the slopes of $\ln \left(\phi / T_{\mathrm{p}}^{2}\right) v s .1 / T_{\mathrm{p}}$ plots and becomes [22];

$$
\ln \left(\frac{\Phi}{T_{\mathrm{p}}^{2}}\right)=-\frac{E}{R T_{\mathrm{p}}}+\ln \left(\frac{A R}{E}\right)
$$

Dobreva et al. [23] developed the method for the crystallization kinetics of molten polymers in the presence of nucleating agents. The following relationship was defined in the case of the non-isothermal crystallization process

$$
\log q \approx \text { const }-\frac{B}{2.3 \Delta T^{2}}
$$

where $q$ is the rate of crystallization, $\Delta T$ is equal to the difference between $T_{\mathrm{m}}$ and $T_{\mathrm{p}} . T_{\mathrm{m}}$ denotes the melting temperature and $T_{\mathrm{p}}$ is the temperature at which the peak value of the $\mathrm{d} \alpha / \mathrm{d} T$ curve is reached. $B$ is a parameter calculated from Eq. (7).

$$
B=\omega \frac{\sigma^{3} V_{\mathrm{m}}^{2}}{3 k_{\mathrm{B}} T_{\mathrm{m}} \Delta S_{\mathrm{m}}^{2} n}
$$

where $V_{\mathrm{m}}, \Delta S_{\mathrm{m}}, k_{\mathrm{B}}, \sigma$ and $\omega$ represent molar volume of the crystallizing substance, entropy of melting, Boltzman constant, specific surface tension and geometrical factor, respectively [9, 23].

The other important parameter in the crystallization of polymer composites is the activity of the filler. The activity of the filler gives information about the adhesion between filler and polymer. The nucleation activity parameter $(\phi)$ defined in Eq. (8) is equal to the ratio of the value of $B$ for the filled polymer to that of the unfilled polymer $[9,15]$.

$$
\phi=\frac{B^{*}}{B^{0}}
$$

where $B^{*}$ and $B^{0}$ represent the values of $B$ for filled and unfilled polymer, respectively. Also, it is possible to obtain the $B$ values from the experimental slopes in the $\log q v s .1 / \Delta T^{2}$ graph according to Eq. (6). The parameter $\phi$ can be estimated from Eq. (10). The activity related to the parameter $\phi$ indicates that a lower value of $\phi$ deals with a higher value of activity. The reduction in the parameter $\phi$ leads to the decrease in lamella thickness and surface energy of the polymer (PP) phase [24]. Also, the properties of the composite can be changed by varying the activity of the filler with different treatments. 
Gutierrez et al. [15] and Alonso et al. [9] investigated the effect of silane coupling agents on the activity of talc in the polypropylene-talc composites using DSC. They concluded that the $\phi$ value of the treated filler is closer to zero, so the treated filler is more active than the untreated filler. Consequently, the interaction between the filler and the matrix will be higher and the filler will influence the matrix structure to a greater extent because of the high activity of the filler. This higher interaction can be used to explain the improvement in the mechanical performance of the composite. As a result of these studies, the parameter $\phi$ is adequate to quantify in a form of the matrix-filler interaction.

\section{Experimental}

\section{Materials and methods}

Isotactic (MH-418) polypropylene in pellet form supplied from PETKIM Petrochemical Co. and clinoptilolite rich natural zeolite from Gördes (Western Anatolia) were used. Three different types of surface modifiers; 3-aminopropyltriethoxysilane (AMPTES), 3-mercaptopropyltrimethoxysilane (MPTMS) and methyltriethoxysilane (MTES) supplied from Fluka and Merck were used to improve compatibility of zeolite with the hydrophobic PP. Also, epoxidized soybean oil (EPSO) supplied from Akdeniz Kimya was used as a plasticizer.

Surface modifications of zeolite and preparation of composites were reported in detail in the previous paper [8]. PP composites containing 2 and 4 mass\% untreated or treated zeolite were prepared using an Axon BX-18 single screw extruder and an Axon 2R-180 two-roll mill. Epoxidized soybean oil (EPSO) was used at a rate of $5 \mathrm{v} / \mathrm{mass} \%$ of total mass of the PP and the zeolite to improve processability of the $\mathrm{PP}-$ zeolite composites in the extruder. The mixtures were conditioned in a vacuum oven at $80^{\circ} \mathrm{C}$ under $40 \mathrm{kPa}$ pressure for $1 \mathrm{~h}$ to ensure replacement of air in the pores of zeolite with EPSO.

\section{Thermal analyses}

Thermal analyses of the PP-zeolite composite films were conducted using Shimadzu Thermal Gravimetric Analyzer (TG-51) and Shimadzu Differential Scanning Calorimeter (DSC-50) under nitrogen atmosphere with a flow rate of $40 \mathrm{~cm}^{3} \mathrm{~min}^{-1}$. Thermogravimetric analysis was used for the thermal degradation study of PP composites. The experiments were carried out from room temperature to $600^{\circ} \mathrm{C}$ at a heating rate of $10^{\circ} \mathrm{C} \mathrm{min}^{-1}$.

Shimadzu Differential Scanning Calorimeter (DSC-50) was used to study the non-isothermal crystallization behavior of PP composites. The samples were heated to $200^{\circ} \mathrm{C}$ at a heating rate of $20^{\circ} \mathrm{C} \mathrm{min}^{-1}$ and held at $200^{\circ} \mathrm{C}$ for $4 \mathrm{~min}$ in order to erase any previous thermal history. Non-isothermal crystallization kinetics was investigated by cooling the samples from 200 to $50^{\circ} \mathrm{C}$ at cooling rates of 5,10 and $20^{\circ} \mathrm{C} \mathrm{min}^{-1}$.

\section{Results and discussions}

\section{Characterization of PP-zeolite composites by $T G$}

Thermal characterization of polypropylene-zeolite composites by TG was performed to investigate the thermal degradation behaviour of the composites and also to determine the zeolite content of the composites. All substances in the composite except the zeolite particles decompose until $600^{\circ} \mathrm{C}$. TG curve of natural zeolite was shown in Fig. 1. The water content of zeolite only decreases until $600^{\circ} \mathrm{C}$. Moreover, the water content and types of water in the zeolite structure can be determined by TG. Knownlton et al. [25] studied the types of water in clinoptilolite. They concluded that the nature of water in clinoptilolite is predominantly dependent on the interactions of water molecules with the $\mathrm{Si}, \mathrm{Al}$ framework. They reported that the three types of water are present in natural zeolite, namely, external water, loosely bound water, and tightly bound water; these are removed from the structure of zeolite at around 75,171 and $271^{\circ} \mathrm{C}$, respectively. TG curve of zeolite in Fig. 1 showed the presence of $12.75 \%$ moisture in the structure of zeolite.

Representative TG curves for PP composites having 2 mass\% zeolite were shown in Fig. 2. The mass losses, onset and termination of degradation temperatures of PP composites containing 2 mass $\%$ untreated and treated zeolite with three different surface modifiers at different concentrations are given in Table 1. As seen in the table, the onset and the termination of degradation temperatures of the composites containing untreated zeolite decrease with the addition of EPS as a plasticizer and 2 mass $\%$ zeolite, respectively. Although the onset

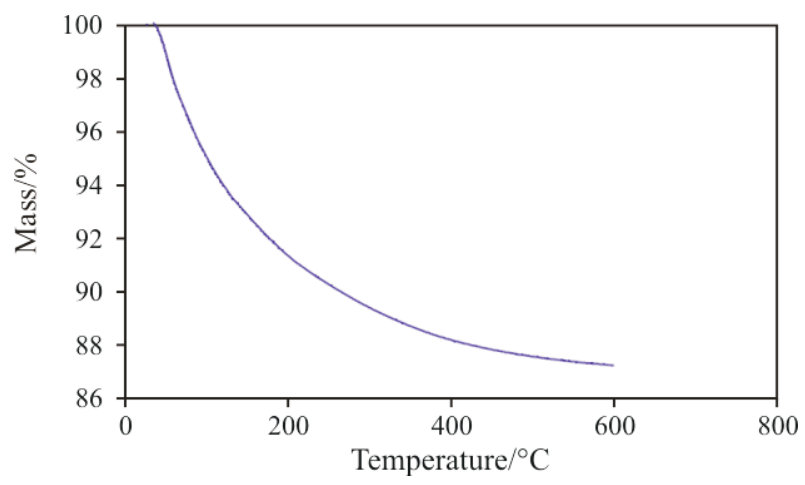

Fig. 1 TG curve of Gördes 1 zeolite 
of degradation temperature of the PP decreases from 257 to $248^{\circ} \mathrm{C}$ with the addition of EPS, the termination temperature of the PP decreases from 537 to $532^{\circ} \mathrm{C}$ with the addition of untreated zeolite. It was found that the EPS have a significant effect on the onset of degradation of PP, but not on the termination of degradation. Also, Özmıhçı et al. [26] studied the effect of zeolite on the thermal degradation of PP by TG. The degradation temperature of $\mathrm{PP}$-zeolite composites without EPS shifts to higher values due to zeolite content in the composites. PP started degradation at $220^{\circ} \mathrm{C}$ but the composites started $10-20^{\circ} \mathrm{C}$ later. Termination temperatures of degradation were found as 550 and $575^{\circ} \mathrm{C}$ for $\mathrm{PP}$ and the zeolite filled PP composites, respectively. The differences obtained from the TG results in two different studies can be explained by the preparation of the composites using different techniques.

The relationship between the mass at the end and beginning of the analysis allows the determination of the zeolite content of the composites. It was observed that the $2 \%$ mass loss untreated and silane treated ( 1 mass $\%$ ) zeolite filled composites changed considerably in the range of 99 and $88.7 \%$. The difference in the mass losses of the filled composites indicates the uneven distribution of zeolite in the matrix. The mass loss values below $98 \%$ shows that the filler content in the composite is higher than 2 mass $\%$. As seen in Table 1, the onset of degradation temperature for the PP-EPS composites increases with the decrease in mass loss or increase in the filler content. Although zeolite retarded the onset temperature of degradation, the termination temperature shifted to the lower temperatures.

TG results of the composites containing PP-EPS matrix and 2 mass $\%$ untreated and treated zeolite with

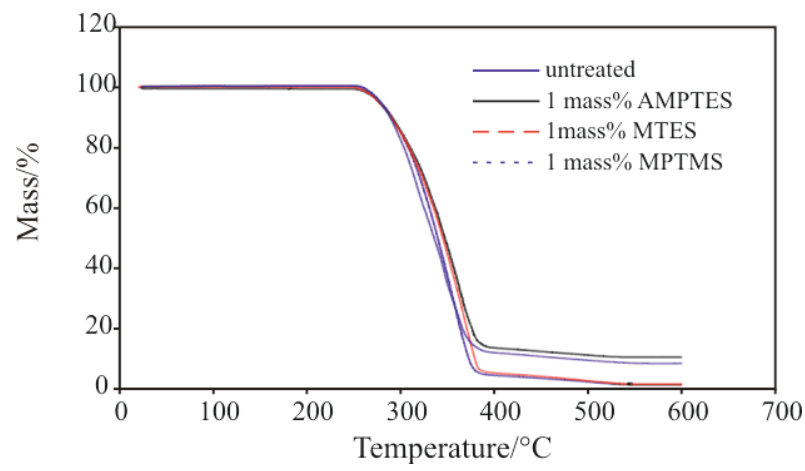

Fig. 2 TG curves of PP-EPS composites containing 2 mass $\%$ untreated and treated zeolite

1 mass\% AMPTES, MTES and MPTMS were shown in Fig. 2 and Table 1. As seen in the figure, degradation of all samples starts around $250^{\circ} \mathrm{C}$ and terminates around $535^{\circ} \mathrm{C}$. The mass losses of the composites containing untreated and treated zeolite with AMPTES, MTES and MPTMS were found as 88.7, 98.8 and $92.1 \%$, respectively. The onset and termination of degradation temperatures of the composites depend on the mass loss of the composites due to the zeolite content. For that reason, the effects of surface modifiers on the degradation behaviour of $\mathrm{PP}$-zeolite composites were not observed because of the difference in the mass losses of the composites. As seen in the table, there is a slight difference in the mass losses of $(0.5,1,1.5$ and 2 mass\%) MPTMS treated zeolite filled composites. Thus, the effect of MPTMS concentration on the degradation behaviour of the composites can be observed. The onset and termination of degradation temperatures of the composites decrease

Table 1 TG results of PP composites

\begin{tabular}{|c|c|c|c|c|c|c|}
\hline Plasticizer & $\begin{array}{c}\text { Zeolite/ } \\
\text { mass } \%\end{array}$ & $\begin{array}{l}\text { Surface } \\
\text { modifier }\end{array}$ & $\begin{array}{c}\text { Surface } \\
\text { modifier } / \text { mass } \%\end{array}$ & $\begin{array}{c}\text { Onset of } \\
\text { degradation } /{ }^{\circ} \mathrm{C}\end{array}$ & $\begin{array}{l}\text { Termination of } \\
\text { degradation } /{ }^{\circ} \mathrm{C}\end{array}$ & $\begin{array}{c}\text { Mass loss at } \\
600^{\circ} \mathrm{C} / \mathrm{mass} \%\end{array}$ \\
\hline \multirow[t]{7}{*}{-} & - & - & - & 257 & 537 & 100 \\
\hline & - & - & - & 248 & 536.5 & 99.4 \\
\hline & 2 & - & - & 251 & 532 & 99 \\
\hline & 2 & \multirow{4}{*}{ AMPTES } & 0.5 & 255 & 532 & 91.1 \\
\hline & 2 & & 1 & 257 & 533 & 88.7 \\
\hline & 2 & & 1.5 & 252 & 534 & 91.7 \\
\hline & 2 & & 2 & 254 & 531 & 90.2 \\
\hline \multirow{8}{*}{ EPS } & 2 & \multirow{4}{*}{ MTES } & 0.5 & 245 & 533 & 99.4 \\
\hline & 2 & & 1 & 250 & 535 & 98.8 \\
\hline & 2 & & 1.5 & 247 & 533 & 99 \\
\hline & 2 & & 2 & 241 & 531 & 90.5 \\
\hline & 2 & \multirow{4}{*}{ MPTMS } & 0.5 & 256 & 534 & 92.2 \\
\hline & 2 & & 1 & 254 & 538 & 92.1 \\
\hline & 2 & & 1.5 & 251 & 534 & 92 \\
\hline & 2 & & 2 & 253 & 530 & 93.7 \\
\hline
\end{tabular}


with the increase of MPTMS concentration at a constant zeolite loading.

As seen in the table, the difference in the mass losses of the composites containing 2 mass\% zeolite indicate the non-homogeneous distribution of the filler in the PP matrix. For that reason, the effect of surface modifier and its concentration on the degradation behaviour of the composites could not be observed easily from the TG analysis. Since the amount of filler in the matrix was not constant, it was difficult to understand which effect caused the degradation temperature fluctuations.

\section{Characterization of PP-zeolite composites by DSC}

The effects of surface modifiers on melting and crystallization behaviour and crystallization kinetics of $\mathrm{PP}$-zeolite composites and also nucleation activity of natural zeolite were investigated.

\section{Melting and crystallization behaviour of PP-zeolite composites}

Melting and crystallization temperatures of polymer composites are important parameters that determine the process conditions affecting the properties of the PP films such as permeability and mechanical properties. Polymer processing occurs in the melt phase and crystallization of the polymer from the melt influences the distribution of the crystallites developed upon cooling from the melt, which determine the final properties of the materials. For that reason, the effects of surface modification of zeolite with silane coupling agents on the crystallization temperature of the composites were studied. The PP-EPS composites containing 4 mass $\%$ untreated and treated zeolite with $1 \mathrm{mass} \%$ silane coupling agents were heated to $200^{\circ} \mathrm{C}$

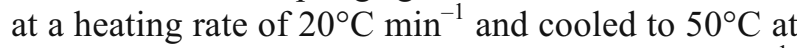
three different cooling rates of 5,10 and $20^{\circ} \mathrm{C} \mathrm{min}^{-1}$. DSC analyses were carried for the composites containing 1 mass $\%$ silane treated filler, because the optimum silane concentration for PP-zeolite composites was determined as 1 mass $\%$ in the previous paper [8].

The melting and crystallization peak temperatures, heat of fusion $\left(\Delta H_{\mathrm{f}}\right)$, heat of crystallization $\left(\Delta H_{\mathrm{c}}\right)$ and $\%$ crystallinity values of the PP composites are tabulated in Table $2 . \%$ crystallinity values were found from $\Delta H_{\mathrm{f}}$ and $\Delta H_{\mathrm{c}}$ of the composites using Eq. (1). As seen in the table, silane coupling agents and zeolite loading have not much effect on the melting peak temperatures of the composites. It was observed that the onset and peak temperatures of crystallization of the composites containing silane treated zeolite show a slight increase at a constant cooling rate compared with the untreated ones and decrease with increase in the cooling rate. The crystallization temperature of the composites shows an increase due to the nucleating ability of zeolite. The crystallization temperature of the composites containing AMPTES treated zeolite shows a significant increase at all cooling rates. The crystallization temperature of the composites containing 4 mass $\%$ untreated zeolite increases from 117.8 to $119.5^{\circ} \mathrm{C}$ with the treatment of zeolite with AMPTES at a cooling rate of $5^{\circ} \mathrm{C} \mathrm{min}^{-1}$. As seen in the table, the crystallization temperatures of the composites shift to the lower temperatures at

Table 2 DSC results of PP composites

\begin{tabular}{|c|c|c|c|c|c|c|c|c|}
\hline $\begin{array}{l}\text { Cooling } \\
\text { rate/ } \\
{ }^{\circ} \mathrm{C} \mathrm{min}{ }^{-1}\end{array}$ & $\begin{array}{l}\text { Surface } \\
\text { modifier }\end{array}$ & $\begin{array}{c}\text { Zeolite/ } \\
\text { mass } \%\end{array}$ & $\begin{array}{c}\text { Melting } \\
\text { temp. } /{ }^{\circ} \mathrm{C}\end{array}$ & $\begin{array}{l}\text { Cryst. } \\
\text { temp. } /{ }^{\circ} \mathrm{C}\end{array}$ & $\begin{array}{c}\Delta H_{\mathrm{f}} / \\
\mathrm{kJ} \mathrm{kg}^{-1}\end{array}$ & $\begin{array}{c}\Delta H_{\mathrm{c}} / \\
\mathrm{kJ} \mathrm{kg}^{-1}\end{array}$ & $\begin{array}{c}\text { Cryst. of } \\
\text { quench } \\
\text { film } / \%\end{array}$ & $\begin{array}{l}\text { Cryst. of } \\
\text { crystal. } \\
\text { peak } \% \text {. }\end{array}$ \\
\hline \multirow{5}{*}{5} & - & - & 161.8 & 115.8 & 73.3 & 96.8 & 35.1 & 46.3 \\
\hline & - & 4 & 163.8 & 117.8 & 81.5 & 93.3 & 38.9 & 44.6 \\
\hline & AMPTES & 4 & 163.1 & 119.5 & 78 & 92.3 & 37.3 & 44.2 \\
\hline & MTES & 4 & 163.3 & 118.1 & 80.1 & 92.5 & 38.3 & 44.3 \\
\hline & MPTMS & 4 & 162.7 & 118.4 & 82.3 & 96.7 & 39.4 & 46.3 \\
\hline \multirow{5}{*}{10} & - & - & 162.5 & 112.4 & 77.2 & 91.8 & 36.9 & 43.9 \\
\hline & - & 4 & 164.3 & 113.6 & 77.7 & 91.4 & 37.2 & 43.7 \\
\hline & AMPTES & 4 & 162.5 & 114.1 & 83.5 & 95.5 & 40 & 45.7 \\
\hline & MTES & 4 & 163.5 & 113.8 & 83.2 & 98.3 & 39.8 & 47 \\
\hline & MPTMS & 4 & 163.5 & 114.2 & 80.3 & 94 & 38.4 & 45 \\
\hline \multirow{5}{*}{20} & - & - & 161.8 & 109.5 & 77.2 & 93.9 & 37 & 45 \\
\hline & - & 4 & 165.5 & 111.1 & 75.9 & 85.6 & 36.3 & 41 \\
\hline & AMPTES & 4 & 162.2 & 113.5 & 80.9 & 97.2 & 38.7 & 46.5 \\
\hline & MTES & 4 & 164 & 111.3 & 73.1 & 88.2 & 35 & 42.2 \\
\hline & MPTMS & 4 & 163.4 & 113.4 & 81.9 & 94 & 39.2 & 45 \\
\hline
\end{tabular}


higher cooling rates. The decrease in crystallization temperatures can be explained by the motion of polymer molecules. At low cooling rates, a long period in the motion of polymer molecules is provided for arrangement of the polymers. The initiation of crystallization of polymers at high cooling rates requires more cooling than that of the polymers at low cooling rates due to the instantaneous decrease in viscosity of polymer and also polymer chain mobility [27, 28].

Figure 3 shows the DSC curves of PP-EPS composites containing 4 mass $\%$ MPTMS treated zeolite at cooling rates of 5,10 and $20^{\circ} \mathrm{C} \mathrm{min}^{-1}$. As seen in the figure, although the melting temperature shows a slight increase from 162.7 to $163.4^{\circ} \mathrm{C}$, the crystallization temperature decreases from 118.4 to $113.4^{\circ} \mathrm{C}$ with increase in the cooling rate. The heat of melting and heat of crystallization values show no significant change with increase in the cooling rate. The heat of melting and the heat of crystallization values were found to be around 81 and $94 \mathrm{~kJ} \mathrm{~kg}^{-1}$, respectively.

As seen in Table 2, \% crystallinity values also show no significant change with increase in the cooling rate and silane treatment. However, it was observed that the heats of melting of the composites were lower than the heats of crystallization. For that reason, \% crystallinity values of quenched composites calculated from the heat of melting were lower than those of the composites calculated from the heat of crystallization. This difference between $\%$ crystallinity values can be explained by the thermal analysis conditions. The $\%$ crystallinity of the quenched composites was a direct indication of the crystallinity of the composites obtained from the extruder. The $\%$ crystallinity values of the composites obtained from crystallization peak were affected by thermal history of the composites. For that reason, the composites in the analyses were heated up to $200^{\circ} \mathrm{C}$ for $4 \mathrm{~min}$ in order to erase any previous thermal history.

Although an increase in crystallinity of the composites was observed with the addition of untreated and treated zeolite, the crystallization behaviour of the composite from the melt shows a slight effect.

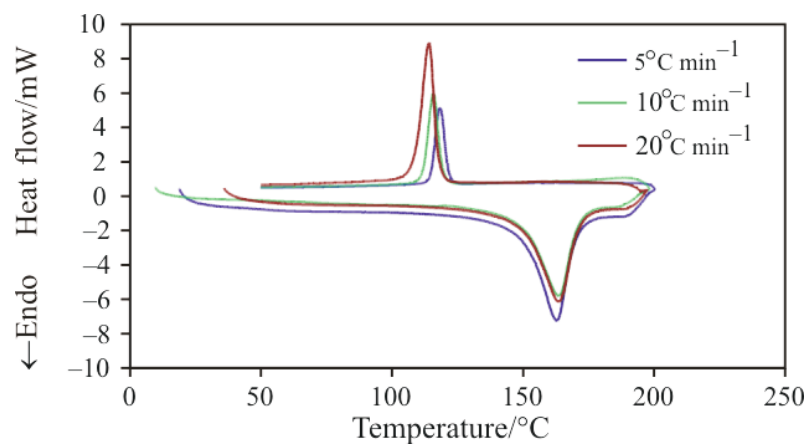

Fig. 3 DSC curves of PP composites containing 4 mass\% MPTMS treated zeolite at different cooling rates
This may be due to the non-homogeneous distribution of the zeolite in the composite and/or activity of zeolite. Also, the peak crystallization temperatures of PP composites increase by the addition of untreated and silane treated zeolite due to the nucleating effect of zeolite. The maximum increase in the crystallization temperatures of the composites was obtained in the AMPTES treated composites. For that reason, the improvement in the mechanical properties of the composites containing AMPTES treated zeolite was expected due to the high crystallization values.

\section{Surface modifiers effects on nucleation activity of natural zeolite}

The effect of inorganic fillers on the crystallization of $\mathrm{PP}$ is related to the filler type according to the inactive or active type filler such as carbon black and talc, respectively [9, 21]. Although inactive fillers have little effect on the rate of crystallization, active fillers can be applied to accelerate the crystallization of the composites. $\Phi$ values, indicating the activity of the filler in Eq. (8) for untreated and surface treated zeolite with silane coupling agents were calculated from $B$ values found from the experimental slopes of the plot of $\log q v s .1 / \Delta T^{2}$, according to Eq. 6 . The lower value of $\Phi$ represents a higher value of activity [9]. Figure 4 represents a plot of $\log q v s$. $1 / \Delta T^{2}$ for the PP-EPS composites having unfilled and filled 4 mass $\%$ untreated and treated zeolite with silane coupling agents. $\Phi$ values of the PP composites containing 4 mass $\%$ untreated zeolite and treated zeolite with 1 mass\% AMPTES, MTES and MPTMS were found as $0.81,0.68,0.86$ and 0.91 , respectively. According to the activity of untreated filler, the increase in the $\Phi$ values for MTES and MPTMS treated zeolite and the decrease in the $\Phi$ value of AMPTES treated zeolite were observed. However, Alonso et al. [9] and Guiterrez et al. (1999) observed the decrease in the $\Phi$ values of talc with surface modification. They obtained that the activity of filler and the nucleating effect were increased with silane treatment. This contrary result in the MTES and MPTMS treated zeolite can be explained by the non-homogeneous distribution of the filler and EPS in the PP matrix. Mitsuishi et al. [29] reported that the activity values of fillers increase with a decrease in particle size. In DSC analyses, it was found that surface modification of zeolite with MPTMS does not lead to good interfacial adhesion between PP and zeolite by comparing the activities of zeolite. However, the mechanical results of PP-zeolite composites presented in the previous paper indicate the presence of adhesion in the case of MPTMS treatment. Also, the most effective silane coupling agent was found as AMPTES by com- 


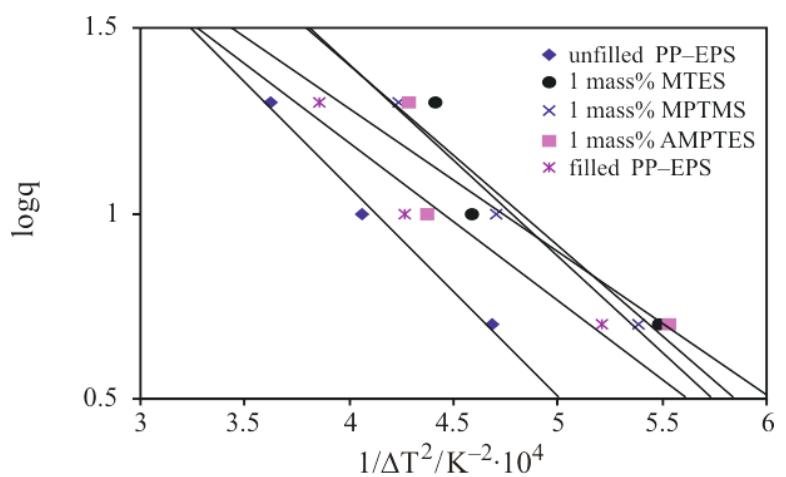

Fig. 4 The $\log q v s .1 / \Delta T^{2}$ plot for unfilled and filled PP-EPS composites containing 4 mass $\%$ untreated and treated zeolite with silane coupling agents

paring the mechanical results of the composites in the previous paper [8]. In addition, DSC analyses also revealed that AMPTES is an effective silane coupling agent for $\mathrm{PP}-$ zeolite composites.

\section{Crystallization kinetics of PP-zeolite composites}

Non-isothermal crystallization kinetics of PP-EPS composites containing 4 mass $\%$ untreated and treated zeolite with 1 mass $\%$ silane coupling agents was determined according to Avrami model. The double logarithmic plot of $\ln (-\ln (1-\alpha)) v s$. $\log t$, known as Avrami plot, for unfilled and filled PP-EPS composites with 4 mass $\%$ untreated and treated zeolite with different silane coupling agents at a cooling rate of $5^{\circ} \mathrm{C} \mathrm{min}^{-1}$ was shown in Fig. 5. Avrami parameters, $n$ and $k$, in Eq. (3) can be determined from the slopes and intercepts of the linear portion of Avrami plot [21, 22, 28, 30]. Avrami parameters of the composites for three different cooling rates were calculated and tabulated in Table 3 . The $n$ values of the composites depend on the form of crystal growth. The $n$ values can vary between 1 and 4, related to the size of crystals. The shape of the crystal changes from rod like to three-dimensional spherulite in this range [31]. The $n$ values obtained from this study were between 2.68 and 3.66 as seen in Table 3 . The change in the $\mathrm{n}$ parameter confirms that the mechanism of crystalline phase growth of PP depend on the presence of zeolite and the cooling rate. The nature of crystal growth was changing from one-dimensional disc to three-dimensional spherulite. The number of nucleation sites increase with the decreasing of $n$ values. For that reason, those having minimum $n$ values at different cooling rates show rapid crystallization. Since $n$ is related to the crystal growth and geometry, the higher the value means the larger the crystals in the composites. It was found that PP-silane treated zeolite composites had larger crystal sizes compared with the untreated ones. As seen in

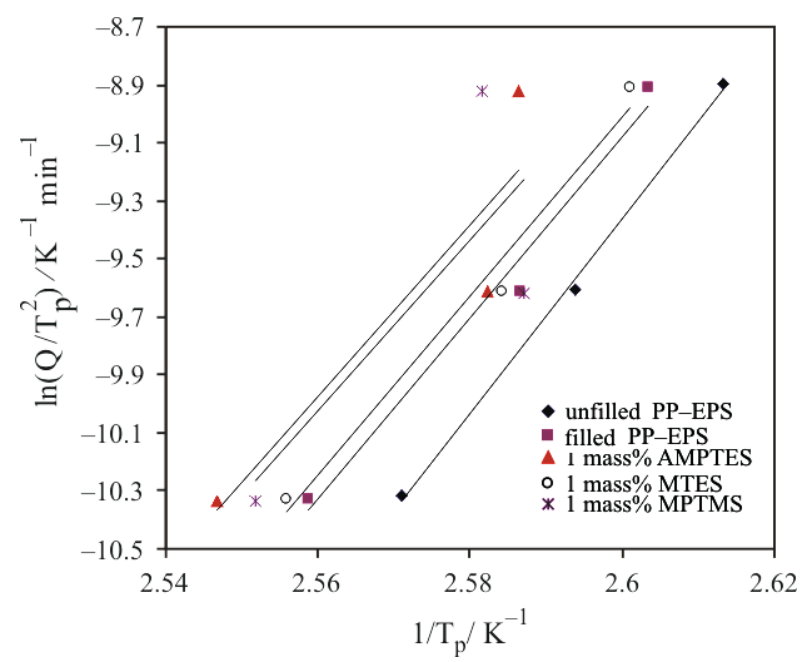

Fig. 5 Avrami plots of unfilled and filled PP-EPS composites containing 4 mass $\%$ untreated and treated zeolite with silane coupling agents at a cooling rate of $5^{\circ} \mathrm{C} \mathrm{min}^{-1}$

the table, the rate constant, $k$, in the Avrami Equation increases with increasing of cooling rate. The $k$ parameters of PP-EPS increase from $5.66 \cdot 10^{-9}$ to $2.43 \cdot 10^{-7}$ with the increase in the cooling rate from 5 to $20^{\circ} \mathrm{C}$ min $^{-1}$. As seen in Fig. 5, and Table $3, k$ values increase with the surface modification of the zeolite. This shows that the rate of crystallization increases with silane treatment.

Kissinger method was also used to determine the activation energy of the composites filled with untreated and treated zeolite with silane coupling agents. According to the Kissinger method, crystallization activation energies of the PP films were determined from the slope of the graph of $\ln \left(Q / T_{\mathrm{p}}^{2}\right)$ vs. $1 / T_{\mathrm{p}}$ as shown in Fig. 6. The crystallization activation energies of PP-EPS composites tabulated in Table 4 were found as 278.2, 259.6, 247.1, 256 and $244.6 \mathrm{~kJ} \mathrm{~mol}^{-1}$ for the unfilled, filled with untreated and treated zeolite with 1 mass $\%$ AMPTES, MTES and MPTMS, respectively. As seen in the table, the crystallization activation energies of the composites decrease with the addition of zeolite and silane treatment. The lower activation energies indicate the faster change of crystallization rate with temperature

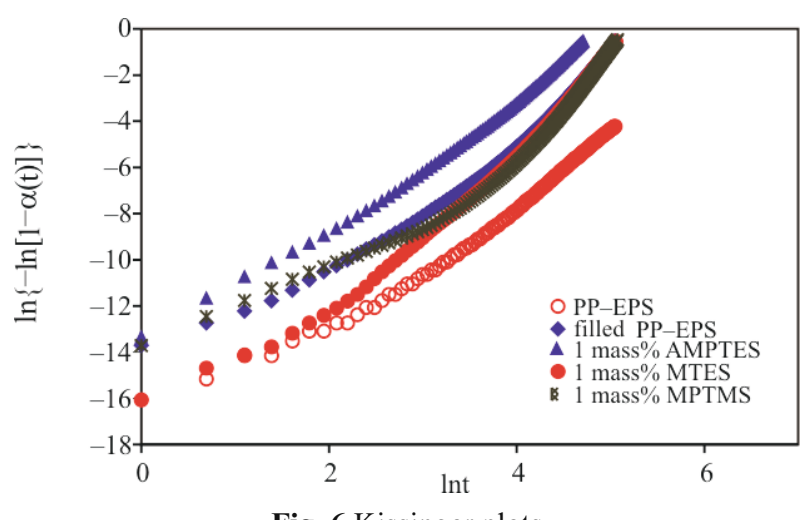

Fig. 6 Kissinger plots 
Table 3 Avrami parameters of the PP-zeolite composites for non-isothermal crystallization

\begin{tabular}{|c|c|c|c|c|c|}
\hline \multirow{2}{*}{ 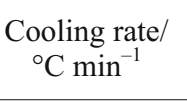 } & \multirow{2}{*}{ Surface modifier } & \multirow{2}{*}{$\begin{array}{l}\text { Amount of surface } \\
\text { modifier/mass } \%\end{array}$} & \multirow{2}{*}{$\begin{array}{c}\text { Zeolite/ } \\
\text { mass } \%\end{array}$} & \multicolumn{2}{|c|}{ Avrami method } \\
\hline & & & & $n$ & $K / \mathrm{s}^{-\mathrm{n}}$ \\
\hline \multirow{5}{*}{5} & - & - & - & 2.87 & $5.7 \cdot 10^{-9}$ \\
\hline & - & - & 4 & 3.08 & $2.6 \cdot 10^{-8}$ \\
\hline & AMPTES & 1 & 4 & 2.87 & $2.7 \cdot 10^{-7}$ \\
\hline & MTES & 1 & 4 & 3.59 & $2 \cdot 10^{-9}$ \\
\hline & MPTMS & 1 & 4 & 3.07 & $1.8 \cdot 10^{-8}$ \\
\hline \multirow{5}{*}{10} & - & - & - & 3.45 & $9.36 \cdot 10^{-8}$ \\
\hline & - & - & 4 & 2.71 & $2.96 \cdot 10^{-8}$ \\
\hline & AMPTES & 1 & 4 & 3.39 & $9.6 \cdot 10^{-8}$ \\
\hline & MTES & 1 & 4 & 2.94 & $7.05 \cdot 10^{-7}$ \\
\hline & MPTMS & 1 & 4 & 3.49 & $6.08 \cdot 10^{-8}$ \\
\hline \multirow{5}{*}{20} & - & - & - & 3.66 & $2.43 \cdot 10^{-7}$ \\
\hline & - & - & 4 & 3.41 & $8.59 \cdot 10^{-8}$ \\
\hline & AMPTES & 1 & 4 & 3.45 & $4.88 \cdot 10^{-7}$ \\
\hline & MTES & 1 & 4 & 3.53 & $1.49 \cdot 10^{-6}$ \\
\hline & MPTMS & 1 & 4 & 2.68 & $4.85 \cdot 10^{-7}$ \\
\hline
\end{tabular}

Table 4 Activation energy values of the PP-zeolite composites for non-isothermal crystallization

\begin{tabular}{lccc}
\hline $\begin{array}{l}\text { Surface } \\
\text { modifier }\end{array}$ & $\begin{array}{c}\text { Amount of surface } \\
\text { modifier/mass\% }\end{array}$ & $\begin{array}{c}\text { Zeolite/ } \\
\text { mass\% }\end{array}$ & $\begin{array}{c}\text { Kissinger method, } \\
\Delta E / \mathrm{kJ} \mathrm{mol}^{-1}\end{array}$ \\
\hline- & - & - & 278.2 \\
- & - & 4 & 259.6 \\
AMPTES & 1 & 4 & 247.1 \\
MTES & 1 & 4 & 256 \\
MPTMS & 1 & 4 & 244.6 \\
\hline
\end{tabular}

and also acceleration of non-isothermal crystallization process $[28,32,33]$. The decrease in activation energy of PP composites indicates the acceleration of non-isothermal crystallization process with the presence of zeolite and surface modification Surface modification results for the lower values, thus the faster change of crystallization with temperature compared to untreated zeolite. It is concluded that nucleating effect increased with the addition of both untreated and treated zeolites to the PP matrix and the nucleating effect of the composites having treated zeolites was more pronounced than that of the untreated composite.

\section{Conclusions}

Thermal analyses indicated that the addition of 2-4 mass \% zeolite and 1 mass $\%$ silane treatment to the PP-EPS matrix did not change significantly the melting and degradation temperatures of the composites. However, these modifications were found to increase the crystallinity and crystallization temperature of the composites due to the nucleating effect of the zeolite.
The influence of the surface modifiers on the interactions between PP and zeolite was determined by comparing the activities of untreated and treated zeolite calculated from crystallization results of PP-zeolite composites. The decrease in activity of AMPTES treated zeolite indicates the presence of good interfacial interactions and adhesion between the polymer matrix and filler particles. As a result, the thermal analyses and crystallization kinetics results revealed that zeolite acts as a nucleating agent and also silane treatment leads to the increase in crystal sizes and the rate of crystallization and decrease in crystallization activation energy.

\section{Acknowledgements}

The authors would like to thank Prof. Devrim Balköse and Prof. Semra Ülkü for their valuable comments and discussions throughout this study. Government Planning Institute (DPT) grant numbers $120290 \mathrm{~K}$ is gratefully acknowledged for financial support of this research. 


\section{MELTING AND CRYSTALLIZATION BEHAVIOUR OF POLYPROPYLENE}

\section{References}

1 Z. Demjén and B. Pukánsky, Polym. Comp., 18 (1997) 741.

2 Z. Demjén, B. Pukánsky and J. Nagy, Composites Part A, 29 (1998) 323.

3 J. R. M. D'almeida and L. H. D. Carvalho, J. Mater. Sci., 33 (1998) 2215.

4 S. Ulutan and D. Balköse, Comp. Int., 4 (1997) 223.

5 S. F. Xavier, J. M. Schultz and K. Friedrich, J. Mater. Sci., 25 (1990) 2428

6 C. M. Liauw, G. C. Lees, S. J. Hurst, R. N. Rothon and S. Ali, Composites Part A, 29 (1998) 1313.

7 M. Y. A. Fuad, Z. Ismail, Z. A. K. Ishak and A. K. M. Omar, Eur. Polym. J., 31 (1995) 885.

8 D. Metin, F. T1hmınlığlu, D. Balköse and S. Ülkü, Composites Part A, 35 (2004) 23.

9 M. Alonso, J. I, Velasco and J. A. Saja, Eur. Polym. J., 33 (1997) 255.

10 G. Bogoeva-Gacera, A. Janevski and E. Mader, Polymer, 42 (2001) 4409.

11 S. Borysiak, J. Therm. Anal. Cal., 88 (2007) 455.

12 M. Y. Fuad, J. Mustafah, M. S. Mansor, Z. A. M. Ishak and A. K. M. Omar, Polym. Int., 38 (1995) 33.

13 T. Hatakeyama and F. X. Quinn, Thermal Analysis - Fundamentals and Applications to Polymer Science, Japan 1994.

14 E. A. Grulke, Polymer Process Engineering, Prentice Hall, New Jersey 1994.

15 S. Diez-Gutierrez, M. A. Rodriguez-Perez, J. A. De Saja and J. I. Velasco, Polymer, 40 (1999) 5345.

16 P. M. McGenity, J. J. Hooper, C. D. Paynter, A. M. Riley and C. Nutbeem, Polymer, 33 (1992) 5215.

17 C. D. Aniello, L. Guadagno, G. Gorrasi and V. Vittoria, Polymer, 41 (2000) 2515.

18 B. J. Hunt and M. I. James, Polymer Characterization, Blackie A \& P, Glasgow 1993.
19 W. Schnabel, Polymer Degradation Principles and Practical Applications, Hanser International 1981.

20 A. R. Horrocks and J. D'souza, J. Appl. Polym. Sci., 42 (1991) 243.

21 M. Mucha and Z. Krolikowski, J. Therm. Anal. Cal., 74 (2003) 549.

22 X. Zhu and D. Yan, Colloid Polym. Sci., 279 ( 2001) 546.

23 A. Dobreva and I. Gutzow, J. Non-Cryst. Sol., 162 (1993) 1.

24 J. I. Velasco, C. Morhain, A. B.Martinez, M. A. Rodriguez-Perez and J. A. Saja, Polymer, 43 (2002) 6813.

25 G. D. Knownlton, T. D. White and H. L. McKague, Clays Clay Miner., 29 (1981) 403.

26 F. Özmıhçı, D. Balköse and S. Ülkü, J. Appl. Polym. Sci., 82 (2001) 2913

27 E. S. Medeiros, R. S. Tocchetto, L. H. Carvalho, I. M. G. Saantos and A. G. Souza, J. Therm. Anal. Cal., 66 (2001) 523.

28 S. H. Kim, S. H. Ahn and T. Hirai, Polymer, 44 (2003) 5625.

30 M. Mucha, J. Mars

29 K. Mitsuishi, S. Ueno, Kodama and H. Kawasaki, J. Appl. Polym. Sci., 43 (1991) 2043.

zalek and A. Fidrych, Polymer, 41 (2000) 4137.

31 R. Progelhof and J. Throne, Polymer Engineering Principles, Properties, Processes, and Tests for Design, Hanser Publishers 1993.

32 G. Liang, J. Xu and W. Xu, J. Appl. Polym. Sci., 91 (2004) 3054.

33 X. Zhu and D. Yan, Col. Polym. Sci., 279 (2001) 546.

DOI: $10.1007 /$ s10973-008-9367-6 